\title{
Biofield Therapies: Helpful or Full of Hype? A Best Evidence Synthesis
}

\author{
Shamini Jain • Paul J. Mills
}

Published online: 24 October 2009

(C) The Author(s) 2009. This article is published with open access at Springerlink.com

\begin{abstract}
Background Biofield therapies (such as Reiki, therapeutic touch, and healing touch) are complementary medicine modalities that remain controversial and are utilized by a significant number of patients, with little information regarding their efficacy.

Purpose This systematic review examines 66 clinical studies with a variety of biofield therapies in different patient populations.

Method We conducted a quality assessment as well as a best evidence synthesis approach to examine evidence for biofield therapies in relevant outcomes for different clinical populations.

Results Studies overall are of medium quality, and generally meet minimum standards for validity of inferences. Biofield therapies show strong evidence for reducing pain intensity in pain populations, and moderate evidence for reducing pain intensity hospitalized and cancer populations. There is moderate evidence for decreasing negative
\end{abstract}

Electronic supplementary material The online version of this article (doi:10.1007/s12529-009-9062-4) contains supplementary material, which is available to authorized users.

S. Jain $(\bowtie)$

UCLA Division of Cancer Prevention and Control Research,

Los Angeles, USA

e-mail: sjain@ucsd.edu

e-mail: shaminijain@ucla.edu

P. J. Mills

Department of Psychiatry, University of California,

San Diego, USA

P. J. Mills

Symptom Control Group, Moores Comprehensive Cancer Center, University of California,

San Diego, USA behavioral symptoms in dementia and moderate evidence for decreasing anxiety for hospitalized populations. There is equivocal evidence for biofield therapies' effects on fatigue and quality of life for cancer patients, as well as for comprehensive pain outcomes and affect in pain patients, and for decreasing anxiety in cardiovascular patients.

Conclusion There is a need for further high-quality studies in this area. Implications and future research directions are discussed.

Keywords Biofield · Therapeutic touch · Qigong · Pain · Cancer. CAM

\section{Introduction}

The concept of subtle energy and methods of its use for healing has been described by numerous cultures for thousands of years. These vital energy concepts (which include the Indian term prana, the Chinese term $c h$ ' $i$, and the Japanese term qi) all refer to so-called subtle or nonphysical energies that permeate existence and have specific effects on the body-mind of all conscious beings. Similar concepts in the West are reflected in the concepts of Holy spirit, or spirit, and can be dated back to writings in the Old Testament as well as the practice of laying on of hands [1].

Despite differences in ontologies of these proposed forces, a common thread within their theories is the development of specific techniques that purport to use subtle energy to stimulate one's own healing process. These are clearly reflected in internal (intrapersonal), movementoriented practices such as yoga, tai-chi, and internal qigong, for example; and are often noted as part of the experience of meditation and prayer. In addition, different 
cultures have developed external (interpersonal) practices that purport to specifically use subtle energies for the process of healing another. These include local or proximal practices such as external Qigong, pranic healing, and laying on of hands, where a healer transmits or guides energy to a recipient who is physically present; as well as distance practices where a healer sends energy to a recipient in a different physical location, such as intercessory prayer or distance healing.

Although many of these practices have been used over millennia in various cultural communities for the purpose of healing physical and mental disorders, they have only recently been examined by current Western empirical methods. The impetus for the research in the West is likely due to a resurgence of public interest in some of these modalities, such as therapeutic touch, healing touch, and Reiki. These modalities, collectively termed by the National Center for Complementary and Alternative Medicine as biofield therapies ${ }^{1}$, began to be more widely taught and used by U.S. nurses in many clinical and hospital settings starting in the 1970s. Concurrently, patient demand and utilization of these modalities outside of conventional medicine settings have prompted scientists and clinicians to examine more closely these so-called healing techniques and their claimed effects. However, such studies are still in their infancy, in part due to the dearth of research funding in this area to conduct large-scale randomized controlled trials (RCTs) of biofield therapies.

Despite the lack of scientific study of biofield therapies, they are actively used by patients with or without the knowledge of their physicians and with or without information based on scientific studies. A survey from the National Center of Health Statistics estimated that over $5 \%$ of respondents had used Reiki, Qigong, or healing rituals [2]. Within clinical populations, energetic and spiritual healing is notably highly used as complementary medicine by cancer, pain, and palliative care patients [2-9].

This review integrates a variety of published studies with different biofield therapies for the purpose of systematically examining whether such modalities might affect positive outcomes for health and reduction of disease symptoms. The review combines clinical studies that examine the efficacy of biofield-based modalities as they are used proximally (i.e., with the patient and practitioner in the same room). Several recent reviews have examined the literature surrounding a specific biofield-based technique

\footnotetext{
${ }^{1}$ NCCAM describes biofields as "putative energy fields [that] have defied measurement to date by reproducible methods. Therapies involving putative energy fields are based on the concept that human beings are infused with a subtle form of energy." (Medicine, 2004)
}

while excluding others [10-14]. Other more integrative reviews have included distant healing and nonhuman populations [15] and/or have been of a purely descriptive nature [16]. In this review, we examine study quality of the current literature, provide a best evidence synthesis of studies with specific clinical populations, and discuss methodological issues as well as directions for future research.

\section{Method}

Methodological details for this review were performed according to QUORUM checklist guidelines and are listed below.

\section{Search Strategy}

A literature search for clinical studies in biofield modalities was conducted using the PUBMED, PSYCINFO, AMED, and CINHAL databases. "spiritual healing," "subtle energy," "energy healing," "biofield healing," "external qi therapy," "emitted chi," "emitted qi," "qi-therapy," "Johrei," "pranic healing," "polarity therapy," "Reiki," "therapeutic touch," and "healing touch." In the case where a multitude of nonclinical studies or articles not related to the subject matter appeared (e.g., the keywords "therapeutic touch" in PUBMED yielded 576 publications), search terms were narrowed to include only clinical studies (e.g., a search with "therapeutic touch" with the limit of "clinical trials" yielded 62 publications). Reference sections of eligible studies and other review papers were also searched for additional studies.

\section{Study Selection}

Inclusion criteria for studies were as follows: (1) published in a peer-review journal in English language, (2) use of a proximally practiced (i.e., practitioner and client in same room) biofield-based modality, and (3) quantitative (biological and/or psychological) endpoints. RCTs are included in this review, as well as within-subject designs that incorporated appropriate pre- and postmeasures and/or historical control groups.

As the nature of this review focused on examining the effects of proximally practiced biofield therapies on human health outcomes, exclusion criteria were as follows: (1) studies incorporating distant healing or intercessory prayer (unless a separate group with only proximal healing was also examined), (2) studies that integrated other modalities with biofield-based modalities in a manner where the interventions could not be separated (e.g., combining Reiki 
with meditation for the same group, with no separate group for Reiki alone), (3) animal, plant, and/or in vitro studies, (4) clinical studies with group assignment but no randomization to groups, (5) purely descriptive studies (e.g., case reports or qualitative review with no formal analysis), and (6) unpublished dissertations (dissertations that were published in a peer-reviewed journal were included).

\section{Data Extraction}

Several types of information were extracted from each study for the purposes of qualitative and systematic data evaluation, including participant characteristics, intervention information, methodological characteristics, statistical methods, and outcomes. Specific information extracted for evaluation follows below.

\section{Study Characteristics and Validity Assessment}

Table 1 depicts the descriptive information extracted for the review, and Table 2 depicts the systematic point rating

Table 1 Descriptive criteria assessed

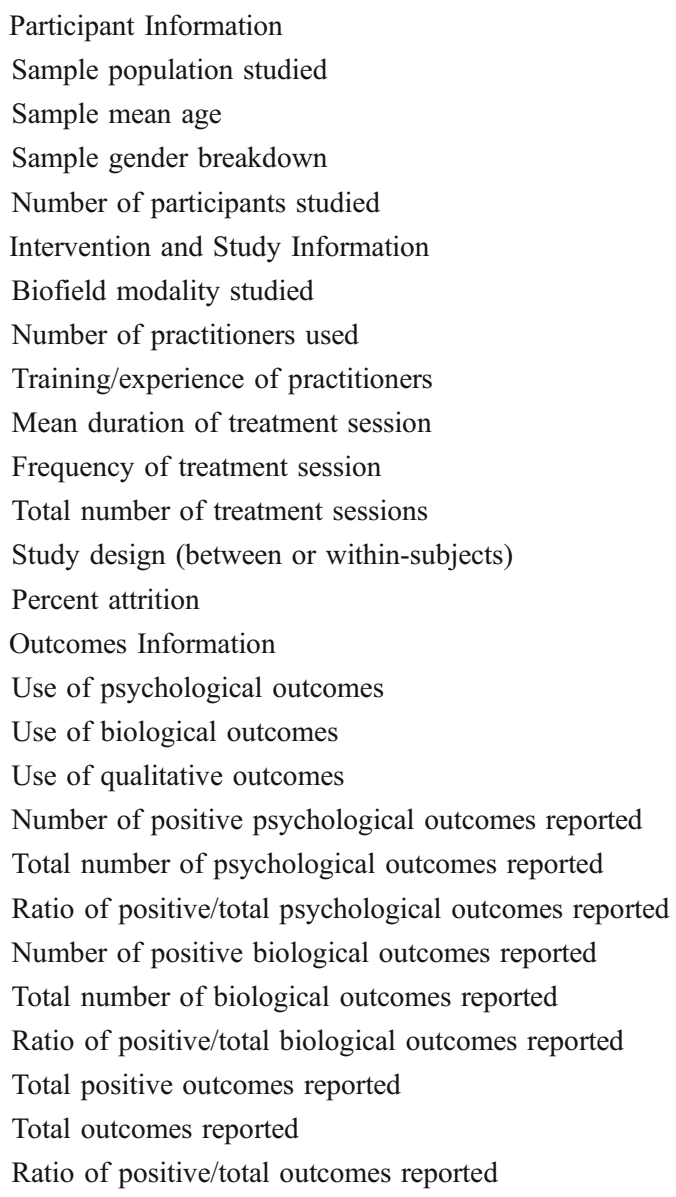

criteria used for the review. Each study was carefully examined for participant characteristics and intervention information and was systematically evaluated for design and methodology, statistical methods, and outcomes reported using the criteria listed below. Both authors conducted study reviews. Interrater reliability for study quality assessment was examined for a subset (35\%) of studies, yielding an intraclass correlation coefficient of 0.95 .

1. Participant information: This information was simply noted for each study, with no point ratings given. Information on patient population, sample size, mean age, gender breakdown, and ethnic breakdown were reviewed.

2. Intervention description: The following aspects of the intervention were noted for each study: modality used, number and training of practitioners, duration of each session, frequency of treatment, and total number of treatment sessions. This information was coded but no rating points were given for these aspects of intervention description.

3. Methodology: Studies were noted to be either betweensubject or within-subject designs (no points were awarded based solely on type of design). Points for methodology were then awarded for specific information. One point was given for the use and description of each of the following: use of a standard control and/or baseline, use of a comparison group, use of a placebo/ nonspecific control, delineation of proper randomization or counterbalancing procedure, description/testing for recipient blinding, description/testing of blindness of outcome assessors, reporting of attrition, and inclusion of follow-up data. Thus, studies could earn 0-8 points for methodology.

4. Statistical methods: One point was given for each of the following: proper data analysis procedure, alpha control, and assessment/use of covariates. A range of points (0-3) was allowed for statistical power based on sample size. Studies that had serious statistical reporting issues (e.g., improper or insufficient information to determine data analysis procedure, failure to report means and standard deviations) that could be threats to inferences were noted as problematic studies and docked two points. Studies with suboptimal data analysis procedures (e.g., series of paired $t$ tests for several different time points in a repeated measures design vs repeated measures analysis; tests between groups on posttest means only instead of repeated measures analysis of variance (rmANOVA), analysis of covariance (ANCOVA), or change scores) were docked one point. Thus, studies could accrue a range of -3 to 6 points for statistical methods. 
Table 2 Study quality rating criteria

NA not applicable

\section{Criteria}

Points Points

awarded deducted

\begin{tabular}{|c|c|c|c|}
\hline \multirow{8}{*}{$\begin{array}{l}\text { Methodology } \\
\text { and design }\end{array}$} & Used standard control group or baseline condition & 1 & NA \\
\hline & Used comparison group or condition & 1 & NA \\
\hline & Used placebo/nonspecific control group or condition & 1 & NA \\
\hline & Delineated proper randomization/counterbalancing procedure & 1 & NA \\
\hline & Described/tested for recipient blinding & 1 & NA \\
\hline & Described/tested blinding of outcome assessors & 1 & NA \\
\hline & Reported attrition & 1 & NA \\
\hline & Utilized follow-up data & 1 & NA \\
\hline \multirow{10}{*}{$\begin{array}{l}\text { Statistical } \\
\text { methods }\end{array}$} & Used proper statistical analysis & 1 & NA \\
\hline & Assessed for/adjusted for covariates & 1 & NA \\
\hline & Used alpha control for multiple comparisons & 1 & NA \\
\hline & Reported effect sizes & 1 & NA \\
\hline & Used adequate sample size & & \\
\hline & $n \leq 19$ per group & 0 & NA \\
\hline & $20 \leq n<30$ per group & 1 & NA \\
\hline & $n \geq 30$ per group & 2 & NA \\
\hline & Poor data analysis procedure (i.e., improper statistical analysis) & 0 & -2 \\
\hline & $\begin{array}{l}\text { Suboptimal data analysis procedure (e.g., using series of several } \\
\text { paired } t \text { tests for repeated measures data without alpha control } \\
\text { examining between-group differences for repeated measures data } \\
\text { using only unadjusted posttest means, no means/SD reported) }\end{array}$ & 0 & -1 \\
\hline \multirow{3}{*}{$\begin{array}{l}\text { Outcomes } \\
\text { methods }\end{array}$} & Used reliable and valid measures & $0-1$ & NA \\
\hline & Did not use any reliable/valid measure & 0 & -1 \\
\hline & $\begin{array}{l}\text { Utilized more than one outcome area (e.g., biological+ } \\
\text { psychological, psychological+ qualitative) }\end{array}$ & 1 & NA \\
\hline $\begin{array}{l}\text { Total possible } \\
\text { points }\end{array}$ & & 16 & -3 \\
\hline
\end{tabular}

5. Outcomes assessed: Studies were given one point for each of the following: multiple types of outcomes assessed (i.e., biological+psychological, or psychological+qualitative, or qualitative+biological, or all three) and use of reliable/valid measures. With respect to the latter, studies that reported several reliable/valid measures but one or more unreliable/valid measure were scored based on ratio (e.g., a study with five outcome measures but only four reliable/valid measures was given 0.8 points for reliability/validity of measures). Thus, studies could earn from -1 to 2 points on outcomes assessed.

Points from each of the categories were summated to provide an overall rating of quality for each study. Thus, the range for overall study quality could be between -3 and 16 points. The reader may note that these study rating criteria include three of the five criteria used in the Jadad method [17] of study quality evaluation for RCTs: (1) procedure to ensure "double-blinding" (here, of patient and outcomes evaluator) was assessed and was appropri- ate, (2) randomization procedure was described and was appropriate, and (3) withdrawals and dropouts were described. This study did not explicitly include the other two criteria: (1) study was randomized, and (2) study was "double-blind," because this review also included withinsubject clinical trials that were not RCTs (however, between-subject designs did require randomization to groups). Table 3 lists each study with overall study quality ratings.

\section{Best Evidence Synthesis}

Following reviews for quality, studies were grouped by patient populations examined and then by outcomes assessed, in order to determine whether biofield therapies showed efficacy for particular medical ailments or aspects of functioning. Studies had to meet the following minimum criteria to be included in the best evidence synthesis: (1) appropriately conduct and adequately describe data analysis procedures, and (2) include an 
Table 3 List of all studies reviewed, with overall quality ratings and subdomain ratings

\begin{tabular}{|c|c|c|c|c|c|}
\hline Authors & Year Published & Overall Study Rating & Methodology Points & Stats Points & Outcomes Points \\
\hline Cleland et al. & $2006[59]$ & 12 & 6 & 4 & 2 \\
\hline Beutler et al. & $1988[54]$ & 11.5 & 5 & 5 & 1.5 \\
\hline Meehan & $1993[43]$ & 11 & 4 & 5 & 2 \\
\hline Laidlaw et al. & $2006[60]$ & 11 & 5 & 4 & 2 \\
\hline Woods, Craven, \& Whitney & 2005 [49] & 10 & 5 & 4 & 1 \\
\hline Smith et al. & $2003[37]$ & 10 & 4 & 4.5 & 1.5 \\
\hline Quinn & $1989[52]$ & 10 & 5 & 4 & 1 \\
\hline Post-White et al. & $2003[35]$ & 10 & 5 & 3 & 2 \\
\hline Lin \& Taylor & 1999 [22] & 10 & 4.5 & 3.5 & 2 \\
\hline Aghabati, Mohammadi, Esmaiel & $2009[38]$ & 10 & 3 & 6 & 1 \\
\hline Movaffaghi et al. & $2006[61]$ & 9.5 & 4.5 & 4 & 1 \\
\hline Gerard et al. & $2003[23]$ & 9.5 & 4.5 & 3 & 2 \\
\hline Olson, Hanson, \& Michaud & $2003[36]$ & 9 & 4 & 3 & 2 \\
\hline Gillespie, Gillespie, \& Stevens & $2007[34]$ & 9 & 3 & 5 & 1 \\
\hline Redner et al. & $1991[30]$ & 8 & 3 & 3 & 2 \\
\hline Peck & $1998[62]$ & 8 & 2.5 & 3.5 & 2 \\
\hline Gordon et al. & 1998 [29] & 8 & 4 & 2 & 2 \\
\hline Abbot et al. & $2001[3]$ & 8 & 4 & 2 & 2 \\
\hline Turner et al. & $1998[45]$ & 7.5 & 3.5 & 3 & 1 \\
\hline Simington \& Laing & 1993 [63] & 5.5 & 4.5 & 1 & 2 \\
\hline Randolph & $1984[64]$ & 7.5 & 3 & 2.5 & 2 \\
\hline Jang \& Lee & $2004[65]$ & 7.5 & 5 & 2 & 0.5 \\
\hline Yang, Kim \& Lee & $2005[24]$ & 7 & 3 & 3 & 1 \\
\hline Naito et al. & $2003[66]$ & 7 & 4 & 2 & 1 \\
\hline Laidlaw et al. & $2003[67]$ & 7 & 4 & 1 & 2 \\
\hline Gagne \& Toye & $1994[68]$ & 7 & 5 & 1 & 1 \\
\hline Engle \& Graney & $2000[69]$ & 7 & 2 & 3 & 2 \\
\hline Cook, Guerrerio, \& Slater & $2004[70]$ & 6 & 3.5 & 2.5 & 1 \\
\hline Shore & $2004[71]$ & 6.5 & 4 & 1.5 & 1 \\
\hline Seskevich et al. & $2004[53]$ & 6.5 & 3 & 3 & 0.5 \\
\hline Quinn & $1984[51]$ & 6.5 & 1 & 3.5 & 2 \\
\hline Keller \& Bzdek & $1986[31]$ & 6.5 & 2 & 3.5 & 1 \\
\hline Woods \& Dimond & $2002[48]$ & 6 & 3 & 2 & 1 \\
\hline Tsang, Carlson, \& Olson & 2007 [39] & 6 & 3 & 2 & 1 \\
\hline Sundblom et al. & $1994[28]$ & 6 & 3 & 1 & 2 \\
\hline Shiflett et al. & $2002[47]$ & 6 & 3 & 2 & 1 \\
\hline MacKay et al. & $2004[55]$ & 6 & 2 & 2 & 2 \\
\hline Lee et al. & $2005[72]$ & 6 & 2 & 2 & 2 \\
\hline Cox \& Hayes & 1999 [46] & 6 & 1 & 3 & 2 \\
\hline Vitale \& O'Connor & $2006[44]$ & 5.5 & 2 & 1.5 & 2 \\
\hline Lee et al. & 2003 [73] & 5.5 & 2 & 3 & 0.5 \\
\hline Krieger & $1976[74]$ & 5.5 & 1 & 3.5 & 1 \\
\hline Dixon & $1998[75]$ & 5.5 & 2 & 2 & 1.5 \\
\hline Blankfield et al. & $2001[76]$ & 4.5 & 3 & 0.5 & 2 \\
\hline Wilkinson et al. & $2002[77]$ & 4 & 2 & 1.5 & 1.5 \\
\hline Sneed et al. & $2001[56]$ & 5 & 1 & 3 & 1 \\
\hline Pohl et al. & $2007[78]$ & 5 & 3 & 1.5 & 0.5 \\
\hline Olson et al. & 1997 [79] & 5 & 3 & 1 & 1 \\
\hline Lee et al. & $2001[25]$ & 5 & 1 & 2 & 2 \\
\hline
\end{tabular}


Table 3 (continued)

\begin{tabular}{|c|c|c|c|c|c|}
\hline Authors & Year Published & Overall Study Rating & Methodology Points & Stats Points & Outcomes Points \\
\hline Laidlaw et al. & $2005[41]$ & 5 & 3 & 1 & 1 \\
\hline Brooks, Schwartz et al. & $2006[80]$ & 5 & 2 & 2 & 1 \\
\hline Lee et al. & $2001[32]$ & 5 & 2 & 1 & 2 \\
\hline Roscoe et al. & $1995[81]$ & 4 & 2 & 1 & 1 \\
\hline Lee et al. & $2003[26]$ & 4 & 2 & 0.5 & 1.5 \\
\hline Lee et al & $2005[72]$ & 4 & 1 & 2 & 1 \\
\hline Ireland & $1998[82]$ & 4 & 1 & 1 & 2 \\
\hline Wardell \& Engebretson & $2001[83]$ & 4 & 1 & 1 & 2 \\
\hline Crawford, Leaver, \& Mahoney & $2006[84]$ & 4 & 2 & 1 & 1 \\
\hline Olson \& Hanson & 1997 [27] & 3.5 & 1 & 2 & 0.5 \\
\hline Lee et al. & $2003[33]$ & 3 & 1 & 1 & 1 \\
\hline Larden, Palmer \& Jannesen & $2004[85]$ & 3 & 4 & -2 & 1 \\
\hline LaFreniere et al. & $1999[86]$ & 3 & 1 & 0 & 2 \\
\hline Lee, Rim, \& Kang & $2004[87]$ & 2 & 1 & 1 & 0 \\
\hline Giasson \& Bouchard & $1998[42]$ & 2.5 & 1 & 1 & 0.5 \\
\hline Denison & $2004[88]$ & 2 & 1.5 & -0.5 & 1 \\
\hline Taylor \& Lo & $2001[89]$ & 1 & 1 & -1 & 1 \\
\hline
\end{tabular}

${ }^{\text {a }}$ Studies noted as problematic due to poor or incomplete reporting of study analysis procedures

adequate control, comparison, or placebo control group or condition. Levels of evidence, akin to those reported in previous best evidence synthesis reviews (e.g., [18]), were assessed separately for the efficacy of biofield therapies for specific patient populations and underlying outcomes. Stipulations for levels of evidence were as follows:

Level 1. Strong evidence as indexed by findings in two or more high-quality RCTs and by generally consistent evidence in other studies.

Level 2. Moderate evidence as indexed by at least one high-quality RCT and supplemented by findings in at least one lower quality RCTs or highquality quasi-experimental study.

Level 3. Limited evidence as indexed by more than one lower quality quasi-experimental study and/or lower quality RCT.

Level 4. Conflicting evidence as indexed by the existence of multiple studies with conflicting results on identical outcomes, such that the number of studies reporting positive vs null outcomes were nearly equal to each other.

Studies were rated as high or low quality based on median scores of quality score ratings. Evidence for an effect for the given biofield therapy was determined by whether the null hypothesis was rejected at a significance level of $p<0.05$ for the outcome(s) examined, such that the biofield therapy showed positive results.

\section{Results}

\section{Study Information}

This search strategy initially yielded 88 clinical studies using the inclusion criteria mentioned above. Of these, eight were excluded for failure of randomization to groups, four were excluded for providing only descriptive information about groups with no analyses, three were excluded for integrating another mind-body intervention with proximal healing, three were excluded for solely examining effects of healing on practitioners with no clinical outcomes/analyses solely for recipients, and four were excluded for integrating or comparing only distant healing with proximal healing. Thus, a total of 66 studies were examined in this review.

Of the 66 studies reviewed, 52 were between-subjects randomized controlled trials, and 14 were within-subject repeated measures designs with appropriate baseline/control conditions. Of the between-subjects designs, 31 utilized a mock or placebo-controlled treatment group, 11 utilized comparison groups, and 32 utilized no treatment or treatment-as-usual control groups (some studies utilized more than one of these groups; e.g., a wait-list control and comparison group). In terms of the biofield interventions used, 27 used therapeutic touch, 10 used Qigong, 10 used Reiki, 5 used spiritual healing, 5 used healing touch, 5 used Johrei, 2 used laying on of hands, 1 used Johnson bioenergy, and 1 used polarity therapy. 
Nearly all studies reported sufficient basic information such as participant number, gender, age, and clinical condition. Disappointingly, $69 \%$ of studies failed to report on ethnic breakdowns of the sample. Most studies provided adequate information on intervention details, including modality used, number and experience of practitioners, length of intervention, and number and frequency of treatment sessions. The length of healing sessions reported ranged from 3 to $90 \mathrm{~min}$; the average was $23 \mathrm{~min}$, and the median was $17.5 \mathrm{~min}$. Studies reported a range of treatment sessions from one to 15 ; the average was four treatment sessions, and the median was 3 .

\section{Systematic Quality Ratings}

The range of overall study quality for all reviewed publications was between one to 12 ; the mean score was 6.4 , and the median was 6 . Thus, according to the review criteria stipulated, the average study was of medium quality. Chi-square analyses with study quality split into high and low based on median score indicated that studies of higher quality had significantly more points assigned for statistical and methodological criteria ( $p<0.015$ in both cases); there was no difference between high- and low-quality studies in terms of outcome rating criteria (i.e., using reliable and valid measures and/or using multiple measures; $p=0.35$ ).

Studies could earn from 0 to 8 possible points for methodology; the range of points for reviewed studies was from 1 to 6 , with the mean score being 2.9 and the median 3 . Thus, studies overall could have improved by better reporting of methodology. For example, although all between-group studies reported randomization to groups, just over half actually delineated the randomization procedures. Similarly, under a third of studies reported blinding of outcome assessors, and of those that utilized placebo-controlled designs, only $34 \%$ described strategies for testing for blinding of participants to condition. Only 53\% of studies reported attrition rates; of those studies, the average attrition rate was $18 \%$, with the median being $14.5 \%$.

Studies could earn from -2 to 6 points on statistical criteria; the range of statistical points for all studies was from -2 to 5 , with a mean of 2.2 and a median of 2 . Thus, the average study scored fairly low on statistical criteria. This was primarily due to lack of assessment/use of covariates, lack of reporting on effect sizes, and lack of alpha control (it should be noted, however, that many studies that did not formally utilize alpha control reported $p$ values that would have remained significant with Bonferroni correction). In addition, the average study for this review used 20-30 participants per group, giving an average and median point rating of 1 for sample size for these reviewed studies. Of the 67 studies, four had serious statistical analysis issues that rendered inferences problem- atic (e.g., not accounting for potential baseline differences along with no reports of means or standard deviations); and six studies had suboptimal or questionable statistical strategies (e.g., inconsistent or poorly described strategies, examining posttest means only with repeated measures data over several different time points). Regression analysis revealed that these ten studies had significantly lower overall study quality than the other 57 studies $\left(F_{(1,61)}=\right.$ 9.1, $p=0.004$ ).

Finally, out of a total of two possible points for outcome measure criteria, the range for this review was from 0 to 2 , with a mean of 1.4 and median of 1.5. Of note is that the average score for reliability and validity of outcome measures assessed for all studies was 0.89 (median was 1); thus, most studies used reliable and valid outcome measures in their investigations, but did not necessarily utilize all types of outcomes (i.e., biological, self-report, qualitative).

Thus, the average study reviewed was of average quality, and minimum quality standards required for validity of inferences (i.e., randomization, use of control or comparison groups or conditions, and appropriate statistical procedures) were generally met. This review reports a lower overall study quality than that reported by Crawford, Sparber, and Jonas [15]; these authors reported a $65 \%$ overall rating on internal validity of the clinical hands-on-healing studies reviewed. However, it should be noted that these authors only included randomized controlled clinical studies, while this study also included within-subject designs with appropriate baseline measurements. This review may, thus, reflect a slightly more accurate assessment of study quality in a larger range of the literature.

\section{Outcomes Results}

Of the 66 studies reviewed, $85 \%$ reported psychological or self-report outcomes, $54 \%$ reported biological or objective functional outcomes, and $9 \%$ examined qualitative reports. Fifty-four percent of the studies utilized more than one outcome domain (mostly biological + psychological outcomes).

\section{Assessing Potential Bias of Problematic Studies}

To determine whether the ten problematic studies may have shown bias in terms of reporting outcomes compared to the other studies, linear regression analyses were conducted on number of positive psychological outcomes reported, number of positive biological outcomes reported, and respective ratios of biological/total and psychological/total outcomes assessed. There was a trend $(p=0.055)$ for these studies to report less positive psychological outcomes compared to the 56 nonproblematic studies; however, they did not significantly differ in terms of reported positive 
biological outcomes or ratio of positive/total outcomes, either for biological or psychological data $(p>0.46$ in all cases). Thus, it did not appear that the ten problematic studies showed bias in reporting more positive outcomes. However, given that these studies rendered problematic inferences due to inappropriate or questionable statistics, these studies were excluded from the best evidence syntheses conducted below.

\section{Best Evidence Syntheses}

In order to glean useful information on the potential efficacy of biofield interventions for particular ailments, we conducted a best evidence synthesis of the remaining nonproblematic studies using the guidelines previously described in the Methods section. Studies were first separated by population. A variety of populations were studied; the most commonly studied patients were those with chronic pain or pain-related disorders $(n=15)$, cancer patients $(n=11)$, postoperative or rehabilitation patients $(n=$ 6), patients with dementia $(n=4)$, and patients with varying cardiovascular ailments $(n=4)$. While some studies utilized student populations $(n=9)$ and a number of studies utilized healthy participants $(n=13)$, these were not included in best evidence syntheses due to the heterogeneity of outcomes assessed within these populations. Also, a few studies examined outcomes for other types of disorders (i.e., mood, substance use), but due to the low number of studies per population and heterogeneous outcomes, best evidence syntheses could not be conducted for these miscellaneous studies. Descriptive information on these studies (student, healthy, and miscellaneous populations) may be found in Tables 4f, g, h electronic (online) supplementary material.

All 67 studies (separated by population/ailment studied) are presented in Tables $4 \mathrm{a}, \mathrm{b}, \mathrm{c}, \mathrm{d}, \mathrm{e}, \mathrm{f}, \mathrm{g}, \mathrm{h}$ as electronic supplementary material. These tables present information on study characteristics, outcomes assessed, results reported, and relative strengths and weaknesses. Best evidence syntheses for pain disorders, cancer, postoperative, dementia, and cardiovascular ailments follow.

\section{Pain-Related Disorders}

Descriptive details for each pain-related study may be found in Table 4a in the electronic supplementary material.

Of the 15 pain-related studies, two were flagged as problematic due to poor statistical procedures and/or reporting and were not included in the best evidence synthesis. Of the remaining 13 studies, using median scores for quality ratings as described in Table 4 , there were nine high-quality RCTs, one high-quality quasi-experimental study, one lower quality quasi-experimental study, and two lower quality RCTs. Seven studies used placebo controls (i.e., mock healing), and seven studies used standard care controls or comparison groups (some studies utilized multiple groups). Six of the 13 studies were specifically targeted toward chronic pain patients, three were with elderly pain patients, and the remaining had varied populations (including arthritis, painful diabetic neuropathy, and restricted movement disorders).

Most studies utilized unidimensional scales (i.e., the visual analog scale or VAS) to rate pain intensity, with fewer studies using more comprehensive pain questionnaires (e.g., the McGill pain rating scale). This is in keeping with the general literature on pain interventions, where the VAS is generally the most frequently used assessment tool [19]. The VAS and related measures (i.e., numeric rating scale or NRS) are reliable and valid and have been used for decades in pain assessment research [20]. Notably, VAS ratings in pain patients have been found to be associated mainly with sensory aspects of pain and may not accurately reflect cognitive and functional aspects of pain reduction [21], but rather, sensory perception of pain intensity.

Seven studies examined pain intensity using the VAS, and one used a similar scale, the NRS. Of these eight studies, six studies (three high-quality RCTs, two lower quality RCTs, and one lower quality within-subjects study) noted significant reductions in pain [22-27]. Four of these studies were placebo control designs, suggesting that the reductions in pain intensity may be beyond nonspecific effects. However, two higher quality RCTs reported null effects on VAS-rated pain $[3,28]$. Thus, while overall studies suggest a strong (level 1) level of evidence for the effects of biofield therapies to reduce pain intensity as noted via the VAS, the emergence of two studies with null findings suggest the need for further study.

Studies using more comprehensive pain assessments (i.e., the McGill or Multidimensional Pain Inventory) provide an inconsistent (level 4) level of evidence for pain relief from biofield therapies. Three high-quality studies [29-31] found significant reductions in these comprehensive pain assessments for biofield groups compared to placebo. However, two high-quality studies, also with placebo controls, did not report significant differences between groups. Importantly, these studies were with varied populations; evidence from future studies will help to better assess whether biofield therapies may be more effective for pain relief for certain types of pain-related disorders.

Eight studies (six high-quality RCTs and two low-quality RCTs) examined mood variables (such as depression, anxiety, and general mood disturbance) as secondary variables in these pain populations. Three studies used the Profile of Mood States (POMS), two used the Hospital Anxiety and Depression scale (HADs), one used the Spielberger State-Trait Anxiety Inventory (STAI), one used 
the Beck Depression Inventory (BDI), and one used VAS measures of anxiety and depression. Findings from these studies suggest conflicting (level 4) evidence on biofield therapies' impact on depression and anxiety as reflected in the current literature. Two high-quality RCTs and two lower quality RCTs reported findings suggesting reductions in anxiety and negative mood [22, 24, 32, 33]. However, four high-quality RCTs $[3,23,28,30]$ suggested no change in these variables. These findings are consistent with the equivocal findings on comprehensive pain measures that incorporate affective components of pain perception, suggesting that overall, there is conflicting evidence on the impact of biofield interventions on affect in pain populations.

Three studies also examined health-related quality of life (QOL) measures in these pain populations; all were highquality RCTs. Abbot et al. [3] reported an increase in SF36-rated physical functioning for healing vs mock healing; this was replicated by Gerard et al. [23], who also reported notable and significant improvements on SF-36-rated energy/vitality. Gillespie, Gillespie, and Stevens [34] also reported borderline significant $(p=0.05)$ findings on a QOL measure specific to their diabetic population. Thus, while studies are definitely limited in this area, currently there is strong evidence (level 1) suggesting that biofield therapies may improve QOL-rated physical functioning as rated by the SF-36.

In summary, data for biofield studies in pain populations suggest strong (level 1) evidence for biofield therapies to provide reductions in pain intensity. However, findings from studies on the effects of biofield therapies on comprehensive assessment of pain reduction are equivocal (level 4), suggesting that the effects of biofield interventions on affective components of pain perception are less clear. In line with these findings, conflicting evidence (level 4) on affective variables such as anxiety and depression suggest the need for further research in this area. Positive findings from a few high-quality RCTs suggest that biofield interventions positively impact health-related quality of life domains such as physical functioning. However, more studies are needed that examine QOL as a primary measure before conclusions can be drawn on effects of biofield interventions on QOL for pain patients. Studies in this area could also be greatly enhanced by the addition of functional measures and biomarkers relevant to the pain disorder of interest.

\section{Cancer Patients}

Descriptive information about cancer studies may be found in Table $4 \mathrm{~b}$ in the electronic supplementary material. There were ten studies that examined outcomes of biofield therapies in cancer patients. Of these, one study had a questionable statistical analysis procedure which rendered inferences problematic; and one study became quasiexperimental due to the healer unblinding his status and quitting the study. These studies were excluded from the best evidence synthesis. The remaining eight studies were conducted with a number of different types of cancer populations, including those undergoing bone marrow transplant, those undergoing chemotherapy treatment, patients with metastatic illness, patients with terminal illness, and other populations. Several studies utilized heterogeneous samples (e.g., gynecological and breast cancer patients). Of these, using median scores for quality ratings as described in Table 4, four studies were rated as high quality and four as lower quality.

Studies were also heterogeneous with respect to specific outcome measures examined; however, overall primary outcomes were related to cancer symptomatology (e.g., fatigue, pain, and nausea) and/or quality of life. Few studies examined physiological or functional measures; two studies examined heart rate, blood pressure, and respiration either during or prepost biofield sessions [35, 36], and one study examined time for engraftment and treatment complications as a result of bone marrow transplant [37].

Four studies examined cancer-related pain. Three studies examined pain acutely (pre- and postsessions). A high quality RCT by Aghabati, Mohammadi, and Esmaiel [38] examined the effects of five days of TT vs. placebo and standard care for a heterogenous group of female cancer patients undergoing chemotherapy. They reported significant decreases in VAS-related pain for those in the TT group as compared to both a placebo and standard care group. Olsen et al. [36]'s smaller, lower quality RCT examined Reiki vs a control group for patients with advanced cancer. Post-White et al. [35]'s high-quality crossover design examined healing touch compared to massage and a nonspecific control (presence) group for breast cancer patients undergoing chemotherapy. Both reported positive outcomes on pain for biofield therapies vs control groups. Post-White et al. [35] also indicated massage to be efficacious in reducing pain compared to the control group, with no significant differences between massage and biofield therapy on pain intensity. However, Post-White et al. also reported no longer term intervention effects on pain index or pain interference for any group. Another pilot, crossover Reiki study [39] with a heterogeneous group of cancer patients reported significant reductions on Edmonton Stage Assessment System ratings of pain over a 2-week intervention period; however, these reductions were not significantly different from the resting condition.

Thus, while the limited number of studies prevents firm conclusions, studies thus far suggest moderate (level 2) evidence for biofield therapies to reduce acute pain in 
cancer. Currently, there is little evidence for longer term pain outcomes in cancer, and it is unclear whether biofield therapies offer benefit over other modalities (such as massage) on pain in cancer.

Three studies specifically examined fatigue as a primary outcome. Aghabati et al.'s [38] high-quality RCT reported significant acute decreases in the Rhoten Fatigue Scale for patients in the Therapeutic Touch vs. placebo and standard care control groups. In the study of Roscoe et al. [40], smaller, lower quality RCT suggested that a short duration of treatment with polarity therapy vs a wait-list control reduced fatigue as measured by the Brief Fatigue Inventory. Tsang et al. [39]'s study suggested that treatment with Reiki reduced fatigue (via the Functional Assessment of Cancer Therapy-Fatigue) over the course of the intervention; however, this reduction was not significantly different from the resting condition. Two other studies examined fatigue as a secondary outcome using the fatigue scale in the POMS. The high-quality, large-scale crossover study of Post-White et al. [35] reported significant reductions in POMS fatigue for healing touch compared to an active control condition (presence). In the study of Laidlaw et al., smaller, lower quality RCT [41] did not find significant reductions in POMS fatigue for metastatic breast cancer patients receiving Johrei compared to hypnosis.

Taken together, these five studies suggest conflicting (level 4) evidence for biofield therapies' effects on reducing fatigue. Notably, each of these studies examined fatigue in slightly different cancer populations at different times of treatment (e.g., radiation therapy, chemotherapy, metastatic disease). Larger scale studies with longer durations of treatment, more comparisons with nonspecific controls (i.e., mock healing groups), and more focused outcomes with respect to cancer-related fatigue will be helpful to better deduce potential positive effects of biofield therapies on cancer-related fatigue.

Three biofield studies with cancer patients also examined quality of life as primary outcomes. Olsen et al. [36] reported increased quality of life after 1 week of Reiki treatments compared to controls, while Laidlaw et al. [41] reported no difference in quality of life after a 4-week Johrei intervention compared to a control group. Giasson and Bouchard's [42] lower quality RCT reported increases in well-being for terminal cancer patients receiving TT vs. a presence control. Thus, the limited data, thus, far suggests conflicting (level 4) evidence for biofield therapies' impact on quality of life for cancer patients; certainly more studies are needed to clarify these initial findings.

Finally, two studies examined the effects of biofield therapies in cancer patients with respect to basic physiological indices of the relaxation response. High-quality crossover study of Post-White et al. [35] reported that healing touch sessions reduced systolic blood pressure and heart rate compared to both a resting control and an active control condition (presence alone). Healing touch also reduced respiratory rate compared to the resting control condition. However, in the study of Olsen et al. [36], smaller scale RCT found no pre- and postsession differences between Reiki and control groups for systolic blood pressure or heart rate, though there was some indication of decreased diastolic blood pressure for those in the Reiki group. Thus, similar to outcomes for well-being, conflicting (level 4) data from limited studies suggest the need for further research to better determine the impact of biofield therapies on physiological indices of the relaxation response.

Thus, best evidence syntheses for effects of biofield therapies for cancer populations may be summarized as follows: There is moderate (level 2) evidence for positive effects on acute cancer pain. To date, there is conflicting (level 4) evidence for longer term pain, cancer-related fatigue, quality of life, and physiologic indicators of the relaxation response. Of note is the relative dearth of total studies in this area compared to the high utilization of this and other complementary and alternative medicine modalities by cancer patients. Further studies are warranted to adequately examine and disseminate information regarding efficacy for troublesome symptomatology in cancer.

\section{Hospitalized and Postoperative Patients}

Descriptive information for studies with hospitalized and postoperative patients may be found in Table $4 \mathrm{c}$ in the electronic supplementary material. Six studies (five high qualities and one low quality, using median scores for quality ratings as described in Table 4) examined effects of biofield therapies on hospitalized or postoperative patients, with most studies examining effects on pain and anxiety.

In the study of Meehan [43], high-quality RCT examined a notably short intervention duration (one 5-min session) of therapeutic touch (TT) vs mock TT or standard care control (pain medication injection) on pain and analgesic medication use for 108 patients who had undergone pelvic or abdominal surgery. Pain medication administration was significantly superior to TT and mock TT in reducing pain; there was a trend $(p=0.06)$ for TT to be associated with reduced pain compared to mock TT. There was also a significant delay in requests for analgesic pain medication for persons receiving TT vs mock TT. A more recent, though lower quality RCT conducted by Vitale and O'Connor [44], also examined effects on postoperative pain, as well as anxiety, on women undergoing abdominal hysterectomy. Three 30-minute sessions of Reiki were given pre- and postoperation and compared to standard care. Results indicated that women in the Reiki group reported significantly less pain at $24 \mathrm{~h}$ postoperation; 
however, there were no differences between groups at 48 and $72 \mathrm{~h}$. The authors also reported that the Reiki group showed significantly decreased STAI-rated anxiety at $72 \mathrm{~h}$ compared to controls.

Two studies attempted to examine effects of biofield therapies on physiologic as well as psychological outcomes for hospitalized patients. Turner et al. [45]'s high quality RCT was designed to examine the effects of five short TT vs mock TT sessions on pain, anxiety, medication use, and lymphocyte subsets for 99 burn patients. The authors reported decreased VAS-rated anxiety in this study, as well as reductions on two of three McGill Pain Indices for TT patients vs mock TT. No differences on pain medication were noted. In terms of lymphocyte subsets, the authors reported that they were unable to examine blood markers on all patients and thus, chose to describe and not analyze results from a convenience sample of 11 patients; thus, no conclusions could be drawn on physiologic parameters. Within-subjects study of Cox and Hayes [46] examined effects of TT on heart rate, blood pressure, and peripheral oxygen saturation for critical care patients, as well as on psychological responses (obtained via qualitative interview). Patients received a mean of two sessions of unknown duration. While no significant changes were found in physiological variables during treatments, themes emerging from qualitative data for patients included feelings of energy and quiescence. Finally, in the study of Shiflett et al. [47], high-quality RCT examined ten 30-min sessions of Reiki vs mock Reiki for poststroke rehabilitation patients. No significant improvements in rehabilitation function or depression were found for Reiki patients vs mock Reiki.

Taken together, studies suggest that for hospitalized patients, there is moderate (level 2) evidence for biofield therapies to reduce anxiety (as indexed by results from high-quality RCT of Turner et al. [45], also supplemented by the results from a lower quality RCT of Vitale and O'Connor [44]). Regarding pain in hospitalized patients, there is moderate (level 2) evidence for acute reductions in rated pain as indexed by high-quality RCT of Turner [45] in burn patients, supplemented with the study of Vitale and O'Connor [44] on the results with postoperative surgery patients. Results from two high-quality studies [43, 45], both with placebo controls, suggest conflicting (level 4) evidence on the efficacy of biofield therapies for reducing pain medication usage (notably, the populations were different-with Meehan studying postoperative pain and Turner et al. studying burn patients). There is insufficient evidence for depression, as well as functional or autonomic outcomes for hospitalized patients; each of these variables was examined by only one study. However, it is notable that each of these studies reported null outcomes on these variables.

\section{Dementia Patients}

Descriptive information for dementia studies may be found in Table $4 \mathrm{~d}$ in the electronic supplementary material. To date, four studies have examined outcomes for dementia patients, and two were noted as problematic studies. The remaining two studies examined the effects of therapeutic touch for dementia patients and were conducted by the same lead author. The first, lower quality study [48] examined the effects of TT using the clinician-rated Agitated Behavior Rating Scale, as well as on salivary and urine cortisol on a small sample $(n=10)$ of persons with Alzheimer's disease. Results indicated significant pre- and posteffects for the vocalization and pacing subscales, but no significant changes in cortisol over time. The second study was a high-quality RCT that examined TT in patients with dementia utilizing the same behavioral measure Woods et al. [49]). This partial replication study reported similar results to the previous pilot study: the TT group showed decreased overall behavioral symptoms as well as decreases in manual manipulation and vocalization compared to a control group. Thus, while data for the effects of biofield therapies for reducing negative behavioral symptoms in dementia is quite limited, there is moderate evidence (level 2) that suggests this to be a promising and important area for additional research. Findings reported here are also corroborated by a recent case study series report [50] that suggests biofield therapies to be helpful in reducing negative symptoms in dementia while also being well tolerated by participants.

\section{Cardiovascular Patients}

Descriptive information for cardiovascular patient studies may be found in Table 4e in the electronic supplementary material. Four high-quality studies have been conducted examining effects of biofield therapies with cardiovascular disorders, with different outcomes examined. Three studies examined anxiety. In her first study with hospitalized cardiovascular patients, Quinn [51] reported significant decreases in state anxiety for persons receiving $5 \mathrm{~min}$ of TT vs mimic TT. However, in a larger subsequent study with patients awaiting open heart surgery, Quinn [52] reported no significant differences between $5 \mathrm{~min}$ of TT vs mimic TT and controls on state anxiety. A relatively recent study by Seskevich, Crater, Lane, and Krucoff [53] reported that cardiovascular patients receiving $30 \mathrm{~min}$ of healing touch (HT) before angioplasty reported significant reductions in VAS-rated worry compared to standard care; however, there was no difference between the HT and stress management and imagery groups. In terms of physiological variables, in the study of Quinn with persons awaiting open-heart surgery [52], no significant differences on 
systolic blood pressure for TT vs mimic TT or the control group; however, the TT group did show significantly decreased diastolic blood pressure compared to the notreatment control group. In the study of Beutler et al. [54], higher quality RCT examined laying on of hands ( $\mathrm{LOOH})$ compared to no treatment and distance healing in hypertensive patients. There were no significant group $\times$ time effects on systolic and diastolic blood pressure, although the LOOH and distant healing groups both showed significant within-subject decreases in diastolic blood pressure.

Thus, while data is particularly limited in this area, results from the high-quality studies of Quinn [51, 52] and Seskevich et al. [53] suggest conflicting (level 4) evidence for biofield therapies to reduce anxiety acutely for cardiovascular patients. High-quality studies of Quinn [52] and Beutler et al. [54] that examined blood pressure suggest there is little evidence for biofield therapies in reducing systolic blood pressure. There is conflicting (level 4) evidence that biofield therapies may reduce diastolic blood pressure compared to no treatment for cardiovascular patients, but more studies examining this outcome in cardiovascular patients are needed. Given that other studies with healthy populations have noted positive outcomes for biofield therapies on cardiovascular indices associated with the relaxation response (i.e., [55, 56]), further examination of biofield therapies' effects on cardiovascular indices seems warranted.

\section{Effects of Treatment Duration and Study Quality on Outcomes}

In order to determine whether treatment session duration, number of treatment sessions, or study quality was associated with reported outcomes, a bivariate (Pearson's product-moment) correlation matrix for the studies was examined. (Although it would have been interesting to examine practitioner experience as a potential predictor variable, heterogeneity of practitioner experience within studies did not make this possible). The total number of treatment sessions was significantly positively associated with number of positive reported psychological outcomes ( $r=0.321, p=0.019$ ), suggesting the possibility of a doseresponse effect on outcomes. However, treatment session duration was not associated with number of positive reported outcomes. Study quality was also not associated with number of positive outcomes.

\section{Discussion}

Biofield-based interventions, used in various cultures for the purposes of eliciting healing responses, have enjoyed a recent resurgence in public interest. In order to better inform patients of the potential benefits or nonbenefits of these modalities, clinicians and scientists within behavioral medicine should familiarize themselves with current theory, practice, and research of such techniques. This review summarizes the state of the science on biofield-based techniques as they are practiced proximally (with practitioner and client in same room). Results from this evidencebased synthesis suggest strong evidence for effects of biofield therapies in decreasing pain intensity in pain populations, moderate evidence for reducing pain in hospitalized populations, and moderate evidence in reducing pain in cancer populations. There is also moderate evidence for biofield therapies to help reduce negative behaviors associated with dementia and moderate evidence for decreasing anxiety in hospitalized populations. Limited findings on biofield therapies for quality of life in pain patients are promising. Findings in other domains (e.g., comprehensive pain outcomes, fatigue and quality of life in cancer patients, and anxiety in cardiovascular populations) are equivocal and generally reflect a paucity of studies that have examined these outcomes. In addition, there is little data available to evaluate the impact of biofield interventions on acute physiology related to the relaxation response, as well as insufficient data to evaluate the impact of biofield therapies on other populations (i.e., mood disorders, substance abuse, pediatric populations).

Findings on biofield therapies to reduce pain intensity among patients with pain and other ailments warrant further investigation with regard to potential mechanism. Given that findings appeared consistent for biofield therapies' efficacy over placebo (five of seven placebo-controlled trials with pain patients reported reductions in pain for biofield vs placebo controls), effects on acute pain appear to be beyond nonspecific effects such as touch or expectation. From a biofield theoretical perspective, acute reductions in pain are understood as a consequence of the movement of stagnant energy that is often associated with pain. Therefore, from this theoretical perspective, continued use of modalities such as biofield therapies should serve to mitigate pain by facilitating movement and increased regulation of vital energy, which may, for example, be associated with decreased inflammation in certain populations. Further larger scale studies will better help elucidate potential longer term benefits of such modalities by including dose-response studies and carefully selected outcomes that are specific for the clinical populations studied. Interestingly, there is conflicting evidence for biofield therapies' effects on more comprehensive pain outcomes, which incorporate cognitive and affective components of pain perception. Should this pattern of findings persist in the literature, it will suggest that mechanisms of action for biofield therapies may differ from more cognitively oriented behavioral medicine modalities (e.g., cogni- 
tive behavioral therapy, mindfulness-based stress reduction), and that the two may serve to complement one another in terms of providing an overall greater sense of pain relief and increased quality of life.

The moderate evidence found for biofield therapies' effects on reducing dementia behaviors and anxiety in hospitalized populations is interesting and warrants further investigation with respect to potential mechanisms and long-term efficacy. Though these studies are relatively few in number, the promising findings in this area, thus, far suggest a need for further research in these specific areas.

A disappointing finding from the review was that $67 \%$ of studies neglected to report ethnic breakdowns of the study sample. Such information may prove to be vital in understanding whether persons from cultures that espouse worldviews matching the holistic principles inherent in biofield therapies respond more positively to these interventions. Researchers in this field are encouraged to take a more careful approach in assessing ethnic and cultural identity as well as worldview along with other pertinent sociodemographic variables.

It will be important for continuing studies in this area to examine whether biofield therapies distinguish themselves from a general relaxation effect that could be achieved by a variety of other empirically supported modalities. Although purported subtle energetic effects cannot be measured directly, bioelectric signal measurement (such as the Gaseous Discharge Visualization [57]) as well as qualitative reports can be examined and may prove to provide interesting comparative information on biofield interventions vs those that are more traditionally cognitive or somatic focused. In addition, examination of specific biomarkers associated with stress and relaxation response systems should be examined to determine impact of biofield therapies vs other modalities on these systems. Examining such comparative data may help to resolve general questions of mechanism and inform the current debate about whether ancient theories supposing subtle energetic effects of these therapies are supported by data, or are better explained by Western theories such as expectation and relaxation effects. Finally, assessment of potential moderators or mediators (e.g., expectation, empathic resonance) of treatment will provide important clinical and research information on the potential mechanisms of action of biofield techniques.

This review has noted limitations. Although systematic, this review is not a meta-analysis. One reason for the decision to approach the data from a systematic but not meta-analytic approach was based on the fact that current studies are very heterogeneous with respect to study quality, types of treatment modalities, length of treatment sessions, and interventions. A formal meta-analysis would have necessitated a more narrow scope in study inclusion and may have excluded the assessment of within-subject designs.
In addition, the research field itself is in its infancy, with many larger scale clinical studies currently underway. Thus, a more definitive meta-analytic approach appears to be premature at this point of assessment. However, this review's reliance on $p$ values and not effect sizes is a notable limitation. It should be noted that of 67 studies, only six reported effect sizes, and very few reported change scores with confidence intervals. Future studies need to include this information in order to better understand the clinical impact of biofield interventions in patients.

Another limitation of this review is the lack of inclusion of studies that reported only qualitative data, as well as a relative lack of systematic assessment of qualitative data that was reported in the studies included. Qualitative data may prove to be vital in understanding the uniqueness of perceived effects of biofield vs other behavioral medicine interventions and thus, may be an essential aspect of study design for this field of research. However, systematic assessment of qualitative data in this review proved difficult as many of the $13 \%$ of studies with qualitative data only reported data for the biofield intervention and not other groups, or failed to report specific methods for analyzing qualitative data. It is hoped that more researchers will follow the lead of some in the nursing field and espouse a "triangulated approach" [58] of combining qualitative with quantitative data for the purpose of providing more completeness in the assessment of biofield vs other therapies.

In conclusion, this best evidence synthesis of proximally practiced biofield therapies suggests that they are promising complementary interventions for reducing pain intensity in numerous populations, reducing anxiety for hospitalized populations, and reducing agitated behaviors in dementia, beyond what may be expected from standard treatment or nonspecific effects. Effects on longer term clinical outcomes are less clear, and more systematic research is needed to clarify findings on fatigue and autonomic nervous system activity. Future suggested research directions include a more thorough assessment of cardiovascular, neuroendocrine, and immune variables, particularly those that are clinically relevant to the disease population. Finally, comparisons of biofield interventions with empirically supported treatments for particular disorders is warranted to determine whether these therapies provide any benefits over and above those from other relaxation-response providing interventions. It is hoped that behavioral medicine clinicians and researchers will continue to examine the research in the area of biofield-based therapies, in order to determine whether these interventions may be a helpful tool in our arsenal to alleviate suffering within patient populations.

Open Access This article is distributed under the terms of the Creative Commons Attribution Noncommercial License which permits any noncommercial use, distribution, and reproduction in any medium, provided the original author(s) and source are credited. 


\section{References}

1. MacNutt F. Healing. Notre Dame: Ave Maria Press; 1974.

2. Barnes PM, Powell-Griner E, McFann K, Nahin RL. Complementary and alternative medicine use among adults: United States, 2002. Adv Data. 2004;343:1-19.

3. Abbot NC, Harkness EF, Stevinson C, Marshall FP, Conn DA, Ernst E. Spiritual healing as a therapy for chronic pain: a randomized, clinical trial. Pain. 2001;91(1-2):79-89.

4. Dy GK, Bekele L, Hanson LJ, Furth A, Mandrekar S, Sloan JA, et al. Complementary and alternative medicine use by patients enrolled onto phase i clinical trials. J Clin Oncol. 2004;22 (23):4810-5.

5. Gotay CC. Use of complementary and alternative medicine in hawaii cancer patients. Hawaii Med J. 1999;58(3):49-51. 54-45.

6. Henderson JW, Donatelle RJ. Complementary and alternative medicine use by women after completion of allopathic treatment for breast cancer. Altern Ther Health Med. 2004;10(1):52-7.

7. Lengacher CA, Bennett MP, Kip KE, Keller R, LaVance MS, Smith LS, et al. Frequency of use of complementary and alternative medicine in women with breast cancer. Oncol Nurs Forum. 2002;29(10):1445-52.

8. Molassiotis A, Margulies A, Fernandez-Ortega P, Pud D, Panteli V, Bruyns I, et al. Complementary and alternative medicine use in patients with haematological malignancies in europe. Complement Ther Clin Pract. 2005;11(2):105-10.

9. Pud D, Kaner E, Morag A, Ben-Ami S, Yaffe A. Use of complementary and alternative medicine among cancer patients in israel. Eur J Oncol Nurs. 2005;9(2):124-30.

10. Astin JA, Harkness E, Ernst E. The efficacy of "distant healing": a systematic review of randomized trials. Ann Intern Med. 2000;132(11):903-10.

11. Chen KW. An analytic review of studies on measuring effects of external qi in china. Altern Ther Health Med. 2004;10 (4):38-50.

12. Miles P, True G. Reiki-review of a biofield therapy history, theory, practice, and research. Altern Ther Health Med. 2003;9 (2):62-72.

13. Wardell DW, Weymouth KF. Review of studies of healing touch. J Nurs Scholarsh. 2004;36(2):147-54.

14. Winstead-Fry P, Kijek J. An integrative review and meta-analysis of therapeutic touch research. Altern Ther Health Med. 1999;5 (6):58-67.

15. Crawford CC, Sparber AG, Jonas WB. A systematic review of the quality of research on hands-on and distance healing: clinical and laboratory studies. Altern Ther Health Med. 2003;9(3 Suppl): A96-104.

16. Benor DJ. Spiritual healing: professional supplement. Southfield: Vision Publications; 2002.

17. Jadad AR, Moore RA, Carroll D, Jenkinson C, Reynolds DJ, Gavaghan DJ, et al. Assessing the quality of reports of randomized clinical trials: is blinding necessary? Control Clin Trials. 1996;17(1):1-12.

18. van Tulder M, Cherkin D, Berman B, Lixing L, Koes B. The effectiveness of acupuncture in the management of acute and chronic low back pain: a systematic review within the framework of the Cochrane Collaboration Back Review Group. Spine. 1993;24:1113.

19. Litcher-Kelly L, Martino SA, Broderick JE, Stone AA. A systematic review of measures used to assess chronic musculoskeletal pain in clinical and randomized controlled clinical trials. J Pain. 2007;8(12):906-13.

20. Jensen MP, Karoly P. In: Turk DC, Melzack R, editors. Self-report scales and procedures for assessing pain in adults. New York: Guilford Press; 2001. p. 15-34.
21. Huber A, Suman AL, Rendo CA, Biasi G, Marcolongo R, Carli G. Dimensions of "unidimensional" ratings of pain and emotions in patients with chronic musculoskeletal pain. Pain. 2007;130 (3):216-24.

22. Lin YS, Taylor B. Effects of therapeutic touch in reducing pain and anxiety in an elderly population. Altern Ther Health Med. 1999;5(6):58-67.

23. Gerard S, Smith BH, Simpson JA. A randomized controlled trial of spiritual healing in restricted neck movement. J Altern Complement Med. 2003;9(4):467-77.

24. Yang KH, Kim YH, Lee MS. Efficacy of qi-therapy (external qigong) for elderly people with chronic pain. Int $J$ Neurosci. 2005;115(7):949-63.

25. Lee MS, Huh HJ, Hong S, Ryu H, Lee H, Chung HT. Psychoneuroimmunological effects of qi-therapy: preliminary study on the changes of level of anxiety, mood, cortisol and melatonin and cellular function of neutrophil and natural killer cells. Stress Health. 2001a;17:17-24.

26. Lee MS, Huh HJ, Jeong SM, Lee HS, Ryu H, Park JH, et al. Effects of qigong on immune cells. Am J Chin Med. 2003;31 (2):327-35.

27. Olson K, Hanson J. Using reiki to manage pain: a preliminary report. Cancer Prev Control. 1997;1(2):108-13.

28. Sundblom DM, Haikonen S, Niemi-Pynttari J, Tigerstedt I. Effect of spiritual healing on chronic idiopathic pain: a medical and psychological study. Clin J Pain. 1994;10(4):296-302.

29. Gordon A, Merenstein JH, D'Amico F, Hudgens D. The effects of therapeutic touch on patients with osteoarthritis of the knee. J Fam Pract. 1998;47(4):271-7.

30. Redner R, Briner B, Snellman L. Effects of a bioenergy healing technique on chronic pain. Subtle Energies. 1991;2(3): 43-68.

31. Keller E, Bzdek VM. Effects of therapeutic touch on tension headache pain. Nurs Res. 1986;35(2):101-6.

32. Lee MS, Yang KH, Huh HJ, Kim HW, Ryu H, Lee HS, et al. Qi therapy as an intervention to reduce chronic pain and to enhance mood in elderly subjects: a pilot study. Am J Chin Med. 2001;29 (2):237-45

33. Lee MS, Jang JW, Jang HS, Moon SR. Effects of qi-therapy on blood pressure, pain and psychological symptoms in the elderly: a randomized controlled pilot trial. Complement Ther Med. 2003;11:159-64.

34. Gillespie A, Gillespie B, Stevens M. Painful diabetic neuropathy impact of an alternative approach. Diabetes Care. 2007;30 (4):999-1001.

35. Post-White J, Kinney ME, Savik K, Gau JB, Wilcox C, Lerner I. Therapeutic massage and healing touch improve symptoms in cancer. Integr Cancer Ther. 2003;2(4):332-44.

36. Olson K, Hanson J, Michaud M. A phase ii trial of reiki for the management of pain in advanced cancer patients. J Pain Symptom Manage. 2003;26(5):990-7.

37. Smith MC, Reeder F, Daniel L, Baramee J, Hagman J. Outcomes of touch therapies during bone marrow transplant. Altern Ther Health Med. 2003;9(1):40-9.

38. Aghabati N, Mohammadi E, Esmaiel Z. The effect of therapeutic touch on pain and fatigue of cancer patients undergoing chemotherapy. Evidence-based Compl and Alt Medicine; eCAM Advance Access published online on February 2, 2008. 2009;1-7.

39. Tsang K, Carlson L, Olson K. Pilot crossover trial of Reiki versus rest for treating cancer-related fatigue. Integrative Cancer Therapies. 2007;6(1):25-35.

40. Roscoe JA, Matteson SE, Mustian KM, Padmanaban D, Morrow GR. Treatment of radiotherapy-induced fatigue through a nonpharmacological approach. Integr Cancer Ther. 2005;4(1):8-13.

41. Laidlaw TM, Bennett MP, Naito A, Dwivedi P, Gruzelier JH. Quality of life and mood changes in metastatic breast cancer after 
training in self-hypnosis or johrei: ashort report. Contemp Hypn. 2005 22(1)

42. Giasson M, Bouchard L. Effect of therapeutic touch on the wellbeing of persons with terminal cancer. J Holist Nurs. 1998;16 (3):383-98.

43. Meehan TC. Therapeutic touch and postoperative pain: a rogerian research study. Nurs Sci Q. 1993;6(2):69-78.

44. Vitale A, O'Connor P. The effect of Reiki on pain and anxiety in women with abdominal hysterectomies: a quasiexperimental pilot study. Holist Nurs Pract. 2006 Nov-Dec;20 (6):263-72.

45. Turner JG, Clark AJ, Gauthier DK, Williams M. The effect of therapeutic touch on pain and anxiety in burn patients. J Adv Nurs. 1998;28(1):10-20.

46. Cox C, Hayes J. Physiologic and psychodynamic responses to the administration of therapeutic touch in critical care. Complement Ther Nurs Midwifery. 1999;5(3):87-92.

47. Shiflett SC, Nayak S, Bid C, Miles P, Agostinelli S. Effect of reiki treatments on functional recovery in patients in poststroke rehabilitation: a pilot study. J Altern Complement Med. 2002;8 (6):755-63.

48. Woods DL, Dimond M. The effect of therapeutic touch on agitated behavior and cortisol in persons with alzheimer's disease. Biol Res Nurs. 2002;4(2):104-14.

49. Woods DL, Craven RF, Whitney J. The effect of therapeutic touch on behavioral symptoms of persons with dementia. Altern Ther Health Med. 2005;11(1):66-74.

50. Meland B. Effects of Reiki on pain and anxiety in the elderly diagnosed with dementia: a series of case reports. Altern Ther Health Med. 2009;15(4):56-7.

51. Quinn JF. Therapeutic touch as energy exchange: testing the theory. ANS Adv Nurs Sci. 1984;6(2):42-9.

52. Quinn JF. Therapeutic touch as energy exchange: replication and extension. Nurs Sci Q. 1989;2(2):79-87.

53. Seskevich J, Crater SW, Lane JD, Krucoff MW. Beneficial effects of noetic therapies on mood before percutaneous intervention for unstable coronary symptoms. Nurs Res. 2004;53(2):116-21.

54. Beutler JJ, Attevelt JT, Schouten SA, Faber JA, Dorhout Mees EJ, Geijskes GG. Paranormal healing and hypertension. Br Med J (Clin Res Ed). 1988;296(6635):1491-4.

55. Mackay N, Hansen S, McFarlane O. Autonomic nervous system changes during reiki treatment: a preliminary study. J Altern Complement Med. 2004;10(6):1077-81.

56. Sneed NV, Olson M, Bubolz B, Finch N. Influences of a relaxation intervention on perceived stress and power spectral analysis of heart rate variability. Prog Cardiovasc Nurs. 2001;16 (2):57-64. 79.

57. Rizzo-Roberts N. Gaseous discharge visualization (gdv) bioelectography: an overview. In: Francomano CA, Jonas WB, editors. Measuring the human energy field: state of the science. Corona del Mar: Gerontology Research Center, NIA; 2002. p. 23-30.

58. Breitmayer BJ, Ayres L, Knafl KA. Triangulation in qualitative research: evaluation of completeness and confirmation purposes. Image J Nurs Sch. 1993;25(3):237-43.

59. Cleland JA, Price DB, Lee AJ, Gerard S, Sharma A. A pragmatic, three-arm randomised controlled trial of spiritual healing for asthma in primary care. Br J Gen Pract. 2006; 56(527):444-9.

60. Laidlaw TM, Naito A, Dwivedi P, Hansi NK, Henderson D, Gruzelier JH. The influence of 10 minutes of the johrei healing method on laboratory stress. Complement Ther Med. 2006;14:127-32.

61. Movaffaghi Z, Hasanpoor M, Farsi M, Hooshmand P, Abrishami F. Effects of therapeutic touch on blood hemoglobin and hematocrit level. J Holist Nurs. 2006;24(1):41-8.
62. Peck SD. The efficacy of therapeutic touch for improving functional ability in elders with degenerative arthritis. Nurs Sci Q. 1998;11(3):123-32.

63. Jang HS, Lee MS. Effects of qi therapy (external qigong) on premenstrual syndrome: a randomized placebo-controlled study. J Altern Complement Med. 2004;10(3):456-62.

64. Simington JA, Laing GP. Effects of therapeutic touch on anxiety in the institutionalized elderly. Clin Nurs Res. 1993;2 (4):438-50.

65. Randolph GL. Therapeutic and physical touch: physiological response to stressful stimuli. Nurs Res. 1984;33(1):33-6.

66. Gagne D, Toye RC. The effects of therapeutic touch and relaxation therapy in reducing anxiety. Arch Psychiatr Nurs. 1994;8(3):184-9.

67. Naito A, Laidlaw TM, Henderson DC, Farahani L, Dwivedi P, Gurzelier JH. The impact of self-hypnosis and johrei on lymphocyte subpopulations at exam time: a controlled study. Brain Res Bull. 2003;62:241-53.

68. Laidlaw TM, Naito A, Dwivedi P, Enzor NA, Brincat CE, Gruzelier JH. Mood changes after self hypnosis and johrei prior to exames. Contemp Hypn. 2003;20(1):25-40.

69. Cook CA, Guerrerio JF, Slater VE. Healing touch and quality of life in women receiving radiation treatment for cancer: a randomized controlled trial. Altern Ther Health Med. 2004;10 (3):34-41.

70. Engle VF, Graney MJ. Biobehavioral effects of therapeutic touch. J Nurs Scholarsh. 2000;32(3):287-93.

71. Shore AG. Long-term effects of energetic healing on symptoms of psychological depression and self-perceived stress. Altern Ther Health Med. 2004;10(3):42-8.

72. Lee MS, Kim MK, Lee YH. Effects of qi-therapy (external qigong) on cardiac autonomic tone: a randomized placebo controlled study. Int J Neurosci. 2005;115(9):1345-50.

73. Blankfield RP, Sulzmann C, Fradley LG, Tapolyai AA, Zyzanski SJ. Therapeutic touch in the treatment of carpal tunnel syndrome. J Am Board Fam Pract. 2001;14(5):335-42.

74. Lee MS, Jeong SM, Jang HS, Ryu H, Moon SR. Effects of in vitro and in vivo qi-therapy on neutrophil superoxide generation in healthy male subjects. Am J Chin Med. 2003;31 (4):623-8.

75. Dixon M. Does 'healing' benefit patients with chronic symptoms? A quasi-randomized trial in general practice. $\mathrm{J}$ R Soc Med. 1998;91(4):183-8.

76. Krieger D. Healing by the "laying-on" of hands as a facilitator of bioenergetic change: the response of in-vivo human hemoglobin. Psychoenerg Syst. 1976;1:121-9.

77. Pohl G, Seeman H, Zojer N, Ochsner C, Luhan C, Schemper M, Ludwig H. "Laying on of hands" improves well-being in patients with advanced cancer. Support Care Cancer. 2007.

78. Olson M, Sneed N, LaVia M, Virella G, Bonadonna R, Michel Y. Stress-induced immunosuppression and therapeutic touch. Altern Ther Health Med. 1997;3(2):68-74.

79. Brooks AJ, Schwartz GE, Reece K, Nangle G. The effect of johrei healing on substance abuse recovery: a pilot study. J Altern Complement Med. 2006;12(7):625-31.

80. Roscoe J, Matteson S, Mustian K, Padmanaban D, Morrow G. Treatment of radiotherapy-induced fatigue through a nonpharmacological approach. Integrative Cancer Therapies. 1995;4 (1):8-13

81. Wilkinson DS, Knox PL, Chatman JE, Johnson TL, Barbour N, Myles Y, et al. The clinical effectiveness of healing touch. J Altern Complement Med. 2002;8(1):33-47.

82. Ireland M. Therapeutic touch with hiv-infected children: A pilot study. J Assoc Nurses AIDS Care. 1998;9(4):68-77.

83. Wardell DW, Engebretson J. Biological correlates of reiki touch (sm) healing. J Adv Nurs. 2001;33(4):439-45. 
84. Crawford S, Leaver V, Mahoney S. Using Reiki to decrease memory and behavior problems in mild cognitive impairment and mild Alzheimer's disease. J Altern Complement Med. 2006;12(9):911-3.

85. Larden CN, Palmer ML, Janssen P. Efficacy of therapeutic touch in treating pregnant inpatients who have a chemical dependency. $\mathrm{J}$ Holist Nurs. 2004;22(4):320-32.

86. LaFreniere KD, Mutus B, Cameron S, Tannous M, Giannotti M, Abu-Zahra H, et al. Effects of therapeutic touch on biochemical and mood indicators in women. J Altern Complement Med. 1999;5(4):367-70.
87. Lee MS, Rim YH, Kang CW. Effects of external qi-therapy on emotions, electroencephalograms, and plasma cortisol. Int $\mathrm{J}$ Neurosci. 2004;112:1493-502.

88. Denison B. Touch the pain away: new research on therapeutic touch and persons with fibromyalgia syndrome. Holist Nurs Pract. 2004;18(3):142-51.

89. Taylor B, Lo R. The effects of healing touch on the coping ability, self esteem and general health of undergraduate nursing students. Complement Ther Nurs Midwifery. 2001; $7(1): 34-42$. 